\title{
Defending Extension Theory: A Response to Kiran and Verbeek
}

\author{
Richard Heersmink
}

Received: 19 January 2011 / Accepted: 2 June 2011

(C) Springer-Verlag 2011

\begin{abstract}
In a recent publication in this journal, Asle Kiran and Peter-Paul Verbeek (hereafter $\mathrm{K} \& \mathrm{~V}$ ) argue that extension theory and the notion of trust it implies are flawed. In this commentary, I defend extension theory against their critique. I first briefly introduce extension theory, then reconstruct K\&V's five arguments against extension theory and demonstrate that four of their five arguments are misplaced.
\end{abstract}

Keywords Extension theory - Instrumentalism · Human-technology relations · Embodiment $\cdot$ Extended cognition

\section{Extension Theory: AVery Brief Introduction}

The idea that technology is an extension of the human organism is a familiar theme in the history of thought about technology. The idea can be traced back to Ernst Kapp and has been further developed by others such as Arnold Gehlen, Marshall McLuhan, Philip Brey and Andy Clark. Let us call the idea that technology extends the human organism the extension thesis and any theory that defends it extension theory. Extension theory is not a unified theoretical perspective on humantechnology relations, but a set of related frameworks that argue that technology is somehow an extension of the human organism. It is helpful to distinguish between weaker and stronger versions of extension theory. Weaker versions - advocated by, for example, Brey (2000), Gehlen (2003) and McLuhan (1964) — commonly argue that certain artefacts amplify and extend human abilities. Telescopes and glasses, for instance, amplify and extend our perceptual system; hammers, cars and pens extend our motor abilities; and notebooks, calculators, computers and other cognitive artefacts extend and enhance our cognitive system. Such artefacts extend human abilities by teaming up with the human perceptual, motor or cognitive system. They

R. Heersmink $(\bowtie)$

Macquarie Centre for Cognitive Science, Macquarie University, Sydney, Australia

e-mail: richard.heersmink@gmail.com 
are defined in relation to but distinct from the human organism, i.e. as two different ontological categories that interact and transform each other, but are separate.

Stronger versions argue that in certain circumstances, these artefacts not only extend human abilities but also are incorporated in and integrated with either the body schema or the cognitive system and co-constitute "new systemic wholes" (Clark 2007). In these new systemic wholes, there is a strong symbiotic and interdependent relation between humans and extending technologies, and human and technology are defined as one functional system in which the distinction between human and technology becomes arbitrary (Feibleman 1967). Furthermore, the extending technology often becomes transparent in use, and we perceive, act or think with and through these devices.

Let me elaborate on stronger versions of extension theory. One can make a (heuristic) distinction between perceptual, motor and cognitive extensions. In the case of perceptual and motor extensions, the concepts of "body schema", "incorporation" and "transparency" are essential to understand the intricate relation between the human organism and the extending technology. A body schema is a non-conscious neural representation of the body's position and its capabilities for action. We are able to incorporate artefacts such as hammers, screwdrivers, pencils, walking canes, cars, glasses and hearing aids into our body schema, thereby enlarging our body schema (De Preester 2010). These artefacts are embodied and are not experienced as objects in the environment but as part of the human motor or perceptual system. When using embodied artefacts to act on the world, such as hammers, pencils and screwdrivers, a subject does not first intend to act on the artefact and then on the world. Rather, a subject merely intends to act on the world through the artefact and does not consciously experience the artefact when doing so. The perceptual focal point is thus at the artefact-environment interface rather than at the agent-artefact interface (Clark 2007). In this sense, embodied artefacts are transparent (Ihde 1990). Because of this transparency and their incorporation into the body schema, they are thought of as co-constitutive of the motor or perceptual system.

Cognitive artefacts such as calculators, computers and navigation systems can, under certain conditions, be incorporated in the human cognitive system in such a way that they can best be seen as literally part of that system. These devices, then, perform functions that are complementary to the human brain (Sutton 2010). There is, furthermore, a two-way interaction when using such devices, and both the brain and the cognitive artefact have a causal role in the overall process, thereby forming a "coupled system". In such coupled systems, the cognitive process is distributed across the brain and artefact, and the artefact is seen as co-constitutive of the extended cognitive system. Remove the technological element from the equation and the overall system will drop in behavioural and cognitive competence. So there is a strong symbiosis and reciprocity in coupled systems. Moreover, what is essential when extending cognition is a high degree of trust in, reliance on, and accessibility of the cognitive artefact (Clark and Chalmers 1998).

The main difference between the weaker and stronger versions lies in the way technology is defined in relation to the human organism. Weaker versions define technology in relation to but distinct from the human organism, whereas stronger versions define technology in relation to the human organism as symbiotic, co-constitutive, and 
define human and technology as one integrated functional system, i.e. as new systemic wholes in which the distinction between human and technology becomes arbitrary.

\section{Kiran and Verbeek's Critique of Extension Theory}

In an appealing and thought-provoking paper, Kiran and Verbeek (2010) criticize extension theory and the notion of trust it implies and argue in favour of a Heideggerian perspective on human-technology relations and trust. K\&V have five arguments against extension theory. First, they make a distinction between the external and internal accounts of human-technology relations. External accounts conceptualize humans and technology as two ontologically distinct categories that can interact but are not intrinsically connected. Internal accounts, on their view, emphasise the intricate and constitutive connections between humans and technology and make clear that "one's subjectivity takes shape in relation to the technology" (p. 420). Extension theory, they argue, is an external account of human-technology relations. Consequently, the intricate and intimate connections between humans and technology remain underexposed.

Second, extension theory "fails to disclose the impact of technology on the constitution of human existence" (p. 418). K\&V claim that extension theory makes a distinction between humans and technology in such a strong way so that the latter cannot constitute the former. Note that this is related to their first argument. Throughout their paper, they depict extension theory as claiming that technologies are external to human beings, merely extend human abilities, and have no genuine transformative impact on human existence.

Third, the transparency of technological extensions reintroduces technological instrumentalism. Instrumentalism claims that artefacts and technologies are mere neutral instruments for pre-given goals and intentions. The artefact or technology merely connects an intention with an effect without shaping or influencing either. This instrumentalist view on technology fails because technologies do shape actions, intentions and effects, thereby implying that technologies are not mere neutral instruments. Since extension theory is committed to an instrumentalist view on technology, $\mathrm{K} \& \mathrm{~V}$ conclude that it is an inadequate theory of humantechnology relations.

Fourth, drawing from Heidegger, $\mathrm{K} \& \mathrm{~V}$ argue that an (embodied) tool should always be understood in its context of use. A claw hammer, e.g. affords pulling things and hitting nails, which points to a certain context in which there are nails and things to pull. Without the claw hammer, we would not perceive or act the way we do in a particular context. So, the world is disclosed in such a way that is partly due to the tool. Because of the relation between a tool and its context of use, some things are accentuated, whilst others fade to the background. Heidegger refers to this phenomenon as having a revealing/concealing structure. K\&V also point to Don Ihde's claims that embodied artefacts display a magnification/reduction structure. When using a perceptual extension such as a telescope, for example, a subject is able to see a magnified version of a small fraction of the night sky, but by doing so, he or she is unable to see the rest of the night sky and takes the magnified perception out of its context. So it magnifies one element whilst 
reducing another. Extension theory ignores the revealing/concealing and magnification/reduction structure of embodied tools.

And fifth, extension theory conceptualizes the notion of trust in technology in terms of reliance. We rely on our extensions to adequately and transparently connect us to the world. Extension theory, furthermore, sees technologies as external devices that might involve risks that need to be managed, but ultimately fails to take into account how interwoven technology is with human existence. The extensionist conception of trust, i.e. merely focusing on the reliability and risks of the technology, overlooks how one's subjectivity is affected. Because of these drawbacks, K\&V develop what they claim to be an alternative notion of trust based on confidence in technology. We should recognize that technology does not merely facilitate the relation to the world but also opens up new ways of being-in-the-world in which humans and the world are constituted in specific ways. We have to actively and deliberately take responsibility for how technology impacts and constitutes our existence and we have to give shape to this in a meaningful way. Thus, instead of focusing on how reliable or risky technology is, we ought to focus on how trustworthy technology is and how we should trust our self to technology. This trusting to technology should not be done uncritically but actively and thoughtfully, which, following Foucault, they refer to as a form of "self-care".

\section{Defending Extension Theory}

Before answering their critique, I address a more general point. $\mathrm{K} \& \mathrm{~V}$ depict extension theory as a unified theoretical framework, which they call "the extensionist idea". They refer to Kapp's concept of organ projection; Gehlen's view on organ substitution; Alfred Lotka's exosomatic organs; Bertram Brookes' idea of computers as exosomatic brains; Gregory Newby's concept of transparent memory extensions; Clark and Chalmers' extended cognition hypothesis; McLuhan's formulation of media technologies as extension of our brain; James Feibleman's organ-artefact circuitry; the augmentationist framework in AI; extropian ideologies claiming that the Internet and other cybertechnologies will allow us to extend our minds, leave our bodies behind and live our life in cyberspace as pure consciousness; and finally, technofantasies about human enhancement technologies such as exoskeletons and sensory augmentations. This is an incredibly wide variety of ideas coming from different disciplines and traditions with different aims and styles which do not have much in common.

All these ideas, concepts and theories are lumped into one theoretical category, which K\&V call "technological extensionism". K\&V do not differentiate between weaker and stronger views and also do not give any criteria by which to decide whether any given views are "extensionist" or not. They attack their specific and homogenized interpretation of extension theory, but generalize their conclusion to all extension theories. However this is not an accurate representation of extension theory since it comes in several guises, each of which makes distinct claims of various strengths. The augmentationist framework in AI, extropian ideologies and technofantasies about human augmentation technologies are constructed with very different aims to, for example, Clark's philosophical case for extension. 


\subsection{Functions, Co-constitution and Co-evolution}

I take up K\&V's first, second and third points simultaneously since they are closely related. $\mathrm{K} \& \mathrm{~V}$ argue that extension theory makes an ontological distinction between humans and technology. Consequently, the intricate and intimate connections between the two domains remain underexposed, and therefore, extension theory "fails to disclose the impact of technology on the constitution of human existence" (p. 418). This is incorrect. In fact, stronger versions of extension theory have argued that the opposite is the case. Strong extension theorists such as Clark and Feibleman have argued that in specific circumstances, there is no clear-cut distinction between humans and their technological extensions. Extension theorists typically (although not necessarily) have a functionalist view on technology, i.e. they analyse functional properties of artefacts in relation to human abilities. When adopting a functionalist perspective on technology, it is hard to distinguish between the human and the technological. In Feibleman's words: "From the point of view of function the distinction between the human body and the tools becomes arbitrary" (1967, p. 330). Humans and their extensions constitute what has been referred to in strong extension theory as "new systemic wholes" (Clark 2007).

Moreover, the notion of extended cognition, an important and leading branch in strong extension theory, conceptualizes the human cognitive apparatus and cognitive artefacts as one information processing system that comprises human brains, bodies and cognitive artefacts. Cognitive artefacts are seen as co-constitutive of the underlying substrate of cognitive processes. Consequently, extended cognitive systems have an inherently hybrid nature, i.e. they have an inherently biological and technological nature. So, in Clark's words: "Our best tools and technologies literally become us: the human self emerges as a soft self” (2007, p. 278). Hence, the connection between the human and the technological element in the new systemic wholes is far from "underexposed" in extension theory. Strong extension theory as outlined by Clark tries to make clear that, in certain circumstances, the human and the technological are interwoven in such an intricate way that they form humanartefact systems. Humans and their technological extensions not only continuously influence each other but also co-constitute each other and form one integrated functional system. Thus, contrary to what $\mathrm{K} \& \mathrm{~V}$ claim, strong extension theory does not fail to disclose the impact of technology on the constitution of human existence.

Understanding the impact of technology on humans is one of the key elements even in weak extension theory. Basically, all extension theorists developed their theories to raise larger questions about human nature, and the social, cultural and psychological impact of technology. McLuhan (1964), for instance, claimed that an extension "numbs" the extended faculty. He even spoke of "self-amputation" of the extended faculty, which, he argued, has great psychological and cultural consequences. According to McLuhan, the wheel is an extension of the motor system and has self-amputated parts of our motor system. The idea being that since the invention of the wheel, we have less well-developed motor systems. He also argued that we should not rely too much on our extensions because otherwise we would become a "servomechanism", i.e. by becoming too reliant on technology we would serve the technology rather than the other way around. 
Also, consider Merlin Donald's (1991) account of the evolution of our cognitive system. According to Donald, our cognitive system has evolved over three stages. The transformation to the third and final stage was induced by the externalization of memory. This began with the development of written language and other symbols and continued with the printing press. These developments enabled us to extend our memory into the material environment and introduced radical new properties into the individual and collective storage and retrieval systems. Consequently, extending our memory has fundamentally changed the human cognitive architecture. Donald's extension theory, thus, makes clear how extending technologies, memory extensions in this case, have a transformative and evolutionary impact on human beings. The point of referring to the works of McLuhan and Donald is to show that extension theorists are greatly concerned with the psychological, cultural and evolutionary influences of the extending technologies on human existence. These extension theorists therefore do not see technologies as mere neutral instruments.

Extension theory does not claim that artefacts are mere neutral, transparent instruments for human ends. It thus differs from the instrumentalist view in which artefacts are mere instruments for human ends and simply connect an intention with an effect. Instrumentalism has been highly controversial in the philosophy of technology. A more plausible perspective is that humans and artefacts continuously influence each other, co-constitute each other and coevolve, which is precisely what stronger versions of extension theory try to make clear.

Consider Feibleman, an extension theorist $\mathrm{K} \& \mathrm{~V}$ paraphrase, quote and indirectly accuse of instrumentalism. He argued that "ordinarily, one thinks of tools as means and of the uses to which they are put as ends. But the situation is no longer that simple, if indeed it ever was. For the tool employed can enter into the business of aims and to some extent at least determine not only their use but also the goals towards they are directed" (1967, p. 332). Furthermore, "men make tools, but in another and equally important sense, it is also true that tools make men. For the tools that men make they afterward use, and by this use they are conditioned" (1967, p. 332). These quotes seem to suggest that Feibleman was well aware that extensions are not mere neutral instruments and do more than merely connecting an intention with an effect: they transform and co-shape (or condition) the human being.

Perhaps $\mathrm{K} \& \mathrm{~V}$ could argue that extension theory may after all not be instrumentalist, but that it does not take into account human-human relations and larger networks of humans and technologies. They could argue that extension theory merely focuses on a single human being that extends itself with technology and is therefore rather limited in scope. This would simply be incorrect. Extension theory has, amongst others, spilled over into cognitive psychology where research is being done on socially extended/distributed cognitive systems such as long-married couples (Sutton et al. 2010). Furthermore, research in distributed cognition, which arguably falls under the rubric of strong extension theory, conceptualizes certain cognitive processes as distributed across several individuals and cognitive artefacts. Edwin Hutchins' (1995) study of ship navigation is a clear example. Extension theory, therefore, 
does more than merely focusing on a human with a single extending artefact and can also account for human-human and larger heterogeneous networks of humans and artefacts. ${ }^{1}$

\subsection{Mediation}

I will now take up K\&V's fourth point. The revealing/concealing and magnification/reduction structure of embodied artefacts is indeed overlooked by both weaker and stronger versions of extension theory. How the extensions are experienced by their users has received a significant amount of attention in extension theory (see Clark 2003, 2007; De Preester 2010). However, how the extensions mediate our experience of the world and how they change our perception is admittedly underexposed in extension theory and clearly needs more attention since it is one of the characteristic features of extending technologies.

\subsection{Trust and Reliance}

Finally, extension theory, as $\mathrm{K} \& \mathrm{~V}$ rightly point out, conceptualizes trust in technology in terms of reliance. Clark and Chalmers, for example, emphasise trust in and reliance on cognitive artefacts as necessary conditions for extending cognition: Otto has to trust in and rely on the information in his notebook in order to extend his memory system (Clark and Chalmers 1998). McLuhan, on the other hand, argued that we should not rely too much on our extensions since otherwise we would become a "servomechanism" of our extensions, i.e. by becoming too reliant on technology we would serve the technology rather than the other way around. So Clark and Chalmers advocate reliance on technological extensions, whereas McLuhan is more critical on this point. But, it is important to note that both Clark and Chalmers as well as McLuhan conceptualize trust in terms of reliance, i.e. we should or should not rely too much on our extensions.

According to $\mathrm{K} \& \mathrm{~V}$, the extensionist conception of trust, i.e. merely focusing on the reliability of the technology, overlooks how one's subjectivity and existence are affected. Consequently, they developed an alternative notion of trust based on confidence that does take into account how one's subjectivity and existence are affected by technology. However, both weak and strong extension theory, as articulated in the previous paragraphs, has a great deal to say about the impact of technology on one's subjectivity and existence. In fact, understanding the impact of technology on human existence is one of the key elements in extension theory. So, although K\&V's conceptualization of trust in terms of confidence is a welcome addition to existing concepts of trust, it is not a critique of trust in terms of reliance since the frameworks in both weak and strong extension theory that conceptualize trust in terms of reliance do take into account how technology impacts human existence.

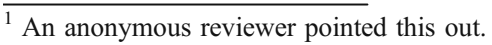




\section{Conclusion}

I hope to have clarified some misunderstandings about extension theory and its implicit notion of trust. First, it is not a homogenized framework on humantechnology relations. Second, strong extension theory as advocated by Clark and Feibleman does, in certain circumstances, not make an ontological distinction between humans and extending technologies; they do not only continuously influence each other but also co-constitute each other and co-evolve. Third, it is not instrumentalist and has a great deal to say about the psychological, cultural and evolutionary influences of extending technologies on human beings. Fourth, extension theory needs to pay more attention to the mediating aspects of extending technologies. And fifth, its notion of trust in terms of reliance is not inadequate in that it does not overlook the powerful ways in which subjectivity is affected.

Acknowledgements I would like to express my gratitude to Asle Kiran, John Sutton, Sadjad Soltanzadeh, as well as two anonymous reviewers for commenting on an earlier draft.

\section{References}

Brey, P. (2000). Technology as extension of human faculties. In C. Mitcham (Ed.), Metaphysics, epistemology and technology. Research in philosophy and technology, vol. 19. Amsterdam: Elsevier.

Clark, A. (2003). Natural-born cyborgs: Minds, technologies, and the future of human intelligence. Oxford: Oxford University Press.

Clark, A. (2007). Reinventing ourselves: The plasticity of embodiment, sensing, and mind. The Journal of Medicine and Philosophy, 32(3), 263-282.

Clark, A., \& Chalmers, D. (1998). The extended mind. Analysis, 58, 10-23.

De Preester, H. (2010). Technology and the body: The (im)possibilities of re-embodiment. Foundations of Science, 16(2-3), 119-137.

Donald, M. (1991). Origins of the modern mind: Three stages in the evolution of culture and cognition. Cambridge: Harvard University Press.

Feibleman, J. K. (1967). The philosophy of tools. Social Forces, 45(3), 329-337.

Gehlen, A. (2003). A philosophical-anthropological perspective on technology. In R. C. Scharff \& V. Dusek (Eds.), Philosophy of technology. The technological condition: An anthology (pp. 213-220). Oxford: Blackwell.

Hutchins, E. (1995). Cognition in the wild. Cambridge: MIT Press.

Ihde, D. (1990). Technology and the lifeworld: From garden to earth. Bloomington: Indiana University Press.

Kiran, A. H., \& Verbeek, P.-P. (2010). Trusting our selves to technology. Knowledge, Technology \& Policy, 23, 409-427.

McLuhan, M. (1964). Understanding media: The extensions of man. Cambridge: MIT Press.

Sutton, J. (2010). Exograms and interdisciplinarity: History, the extended mind, and the civilizing process. In R. Menary (Ed.), The extended mind (pp. 189-225). Cambridge: MIT Press.

Sutton, J., Harris, C. B., Keil, P. G., \& Barnier, A. J. (2010). The psychology of memory, extended cognition, and socially distributed remembering. Phenomenology and the Cognitive Sciences, 9(4), $521-560$. 